\title{
Amylin-induced downregulation of hippocampal neurogenesis is attenuated by leptin in a STAT3/AMPK/ERK-dependent manner in mice
}

\author{
H.-S. Moon • F. Dincer • C. S. Mantzoros
}

Received: 19 October 2012 / Accepted: 19 November 2012 /Published online: 9 December 2012

(C) Springer-Verlag Berlin Heidelberg 2012

\begin{abstract}
Aims/hypothesis Both leptin and insulin sensitivity have been linked with pathophysiological processes involving the central nervous system in general, and the hippocampus in particular, but the role of leptin in hippocampal neurogenesis has not yet been elucidated. Also, no previous studies have evaluated whether amylin or the endogenous insulin sensitiser adiponectin interact with leptin to alter hippocampal neurogenesis in mouse hippocampal neuronal $(\mathrm{HN})$ cells or investigated the role of leptin, amylin or adiponectin signalling in mouse $\mathrm{HN}$ cells.

Methods Hippocampal neurogenesis and leptin, amylin and adiponectin signalling were studied in vitro using mouse H19-7 HN cell lines.

Results Amylin decreased cell proliferation in a dosedependent manner. This effect was diminished by leptin administration and was dependent on signal transducer and activator of transcription 3 (STAT3)/AMP-activated protein kinase (AMPK)/extracellular signal-regulated kinase (ERK). Adiponectin effects were null. We also observed, using immunocytochemical analysis, that amylin decreased activation of microtubule-associated protein 2 , a specific neurite outgrowth marker, and synapsin, a specific synaptogenesis marker. By contrast, both effects were attenuated by co-administration of leptin. Finally, we observed that these
\end{abstract}

Electronic supplementary material The online version of this article (doi:10.1007/s00125-012-2799-3) contains peer-reviewed but unedited supplementary material, which is available to authorised users.

H.-S. Moon · F. Dincer · C. S. Mantzoros

Division of Endocrinology, Diabetes, and Metabolism,

Beth Israel Deaconess Medical Center, Harvard Medical School,

Boston, MA, USA

C. S. Mantzoros $(\bowtie)$

Endocrinology Section, Boston VA Healthcare System,

Harvard Medical School, JP9B52A, 150S. Huntington Ave,

Boston, MA 02130, USA

e-mail: cmantzor@bidmc.harvard.edu effects were blocked by pre-treatment with AG490, a STAT3 inhibitor, and STAT3 small interfering RNA administration. Conclusions/interpretation Our data suggest that amylin in pharmacological concentrations may have a neurotoxic effect whereas leptin in physiological and pharmacological concentrations has a protective effect counteracting amylindecreased hippocampal neurogenesis via STAT3/AMPK/ ERK signalling in mouse H19-7 HN cell lines. Overall, our data support a novel role for leptin and amylin in the processes of mouse hippocampal neurogenesis and provide new insights into the mechanisms of neurogenic regulation.

Keywords Adiponectin · Amylin · Hippocampal neurogenesis $\cdot$ Leptin $\cdot$ STAT3 signalling
Abbreviations
AMPK AMP-activated protein kinase
CNS Central nervous system
ERK Extracellular signal-regulated kinase
HN Hippocampal neuronal
MAP2 Microtubule-associated protein 2
siRNA Small interfering RNA
ssiRNA Scrambled-siRNA
STAT3 Signal transducer and activator of transcription 3

\section{Introduction}

Leptin is an adipocyte-secreted hormone that plays a major role in energy homeostasis and weight balance [1]. Leptin activates not only central nervous system (CNS) networks that suppress appetite [1] but also acts to alter immune function and metabolism [2,3]. Amylin is a 37-amino-acid peptide hormone that is co-secreted with insulin from pancreatic beta cells [4]. The physiological effects of amylin receptor agonism include decreased food intake [4] and reduction of postprandial glucagon release in a glucose- 
dependent manner [5]. Moreover, it has been proposed that a combination of amylin and leptin may be more effective than leptin or amylin alone for treatment of obesity in both animals [2] and humans [5]. Adiponectin, the most abundant adipokine in circulation, is synthesised and secreted by adipose tissue [6]. Adiponectin has insulin-sensitising and anti-inflammatory properties $[6,7]$. It has been shown that mice deficient for adiponectin develop insulin resistance and glucose intolerance when fed a high-fat diet [7]. Conversely, adiponectin replenishment can reduce body weight, improve glucose/lipid homeostasis and increase insulin sensitivity $[7,8]$.

The hippocampus is one of two brain regions where adult neurogenesis persists throughout life [9]. Neurogenesis is regulated by physiological and pathological events and modulated by pharmacological manipulations at any of three primary stages - cell proliferation, differentiation and survival $[9,10]$. Neurogenesis in the hippocampus has been found to be negatively influenced by stress and is suppressed in various animal models of depression [10]. Conversely, new neuron generation in the hippocampus is stimulated by treatment with antidepressants [11]. Also, neurotrophins, growth factors and cytokines have been shown to be capable of modulating neurogenesis of the hippocampus $[12,13]$.

Recent findings demonstrate that leptin facilitates spatial learning and memory [14-16] and produces antidepressantlike effects [17-22]. Amylin has a beneficial effect on the CNS to alter physiological responses to feeding [23]. It has been demonstrated that amylin induces neurotoxicity in embryonic rat hippocampal primary cultures in vitro and this may drive the prominent neurite degeneration in Alzheimer's disease [24]. By contrast, central administration of amylin resulted in impaired memory retention in mice given strong training but had no effect on the retention of mice given weak training [25], suggesting that the mechanisms of action by which amylin alters memory processing in the hippocampus are different for peripheral and central administration. Adiponectin has been proposed to exert multiple regulatory functions primarily through action on the CNS [26]. Also, it has been suggested that adiponectin and other insulin-sensitising hormones may regulate brain function, particularly in relation to processes associated with memory and cognition [27]. It has also been demonstrated that type 2 diabetes is associated with cognitive dysfunction and hippocampus volume; mean hippocampus volume was lower in individuals who had low adiponectin levels compared with individuals who had normal adiponectin levels [28]. Recent studies have indicated that there is an association between hippocampal volume and serum adiponectin levels in patients with type 2 diabetes [28, 29].

Whether leptin regulates hippocampal neurogenesis and whether it activates relevant signalling pathways in hippocampal neuronal $(\mathrm{HN})$ cells remains unknown. Also, direct evidence that amylin or adiponectin contribute to the regulation of hippocampal neurogenesis has not yet been published and no previous study has evaluated amylin or adiponectin signalling in $\mathrm{HN}$ cells or investigated how amylin or adiponectin interact with leptin to alter signalling in $\mathrm{HN}$ cells. In this study, we investigated the effect of leptin, amylin and adiponectin alone or in combination on cell proliferation and differentiation in mouse H19-7 HN cells. We also characterised the possible signalling mechanisms by which leptin, amylin or adiponectin exert their effects on hippocampal neurogenesis in the mouse H19-7 HN cells.

\section{Methods}

Materials Leptin (human, recombinant) was purchased from ProSpecBio (East Brunswick, NJ, USA). Amylin (human, recombinant) was purchased from Phoenix Pharmaceuticals (Burlingame, CA, USA). Adiponectin (human, recombinant) was purchased from R\&D Systems (Minneapolis, MN, USA). All primary and secondary antibodies were purchased from Santa Cruz Biotech (Santa Cruz, CA, USA). The small interfering RNA (siRNA) and scrambled siRNA (ssiRNA) were purchased from Santa Cruz Biotech.

Cell culture The mouse H19-7 HN cell lines were purchased from American Type Culture Collection (Manassas, VA, USA). The cells were grown in DMEM (Life Technologies, Grand Island, NY, USA) with $10 \%$ (vol./vol.) fetal bovine serum. All cells were incubated at $37^{\circ} \mathrm{C}$ in an atmosphere of $5 \% \mathrm{CO}_{2}$ in air, and sub-cultured beyond $80 \%$ confluency. The experiments were performed after serum starvation overnight.

Proliferation assay Cell proliferation assay was performed using the MTT proliferation kit (Sigma-Aldrich, St Louis, MO, USA) according to the supplier's instructions.

Western blotting Western blotting was performed as previously described [30].

Measurement of signal intensity on nitrocellulose membranes after western blotting with various antibodies was performed using Image $\mathrm{J}$ (version 1.46) processing and analysis software (http://rsb.info.nih.gov/ij/, accessed 25 August 2011).

Introduction of siRNA Introduction of siRNA was performed as previously described [30].

Immunocytochemistry Cells were fixed with $0.4 \%$ $p$-formaldehyde (Sigma-Aldrich) in phosphate-buffered saline (PBS; Sigma-Aldrich), $\mathrm{pH} 7.4$, for $30 \mathrm{~min}$. After permeabilisation with $0.1 \%$ (vol./vol.) Triton X-100 (Sigma-Aldrich), cells 
were blocked for $1 \mathrm{~h}$ at $37^{\circ} \mathrm{C}$ with PBS containing $10 \%$ (vol./ vol.) goat serum (Life Technologies) and then incubated with the primary antibody against microtubule-associated protein (mouse monoclonal 1:250 [vol./vol.]; Santa Cruz Biotech) and synapsin I (rabbit polyclonal 1:1,000 [vol./vol.]; Santa Cruz Biotech). After washing with PBS, cells were incubated with the corresponding secondary antibody (Jackson Immunoresearch Laboratories, West Grove, PA, USA). For the nuclear staining, 0.06\% 4,6-diamidino-2-phenylindole (Sigma-Aldrich) was used. After immunostaining, images were collected using an EVOS fluorescence microscope (Advanced Microscopy Group, Bothell, WA, USA). Five to six fields per well were chosen at random and only non-clustered neurons were evaluated to ensure the precision of the measurements. The images were taken at $\times 40$ magnification.

Statistical analysis All signalling data were analysed using Student's $t$ test and/or one-way ANOVA followed by posthoc tests (Bonferroni correction for multiple comparisons). All analyses were performed using SPSS version 11.5 (SPSS, Chicago, IL, USA) and Stata version 11.1 (Stata, College Station, TX, USA).

\section{Results}

Regulation of cell proliferation by leptin, amylin and adiponectin alone in mouse H19-7 HN cell lines Low physiological concentrations of leptin $(0.1-5 \mathrm{ng} / \mathrm{ml})$ had no effect on cell proliferation when compared with control in mouse H19-7 HN cell lines (Fig. 1a). By contrast, we observed that cell proliferation was increased by $\sim 20-40 \%$ at $10-100 \mathrm{ng} / \mathrm{ml}$ of leptin when compared with control in mouse H19-7 HN cell lines. Treatment with amylin in physiological concentrations $(0.1-10 \mathrm{ng} / \mathrm{ml})$ had no effect on cell proliferation in mouse H19-7 HN cell lines (Fig. 1b) but high physiological/pharmacological concentrations of amylin (50-100 $\mathrm{ng} / \mathrm{ml}) \mathrm{de}-$ creased cell proliferation by $\sim 30 \%$ when compared with control. Finally, we observed that cell proliferation was not regulated by adiponectin administration in mouse H19-7 HN cell lines (Fig. 1c).

Regulation of cell proliferation by leptin, amylin and adiponectin in combination in mouse H19-7 HN cell lines Based on the data shown in Fig. 1, we chose two concentrations of leptin, 10 and $50 \mathrm{ng} / \mathrm{ml}$, and checked whether amylin-decreased cell proliferation in mouse H19-7 HN cell lines was diminished by leptin administration. We observed that leptinstimulated cell proliferation was not altered by physiological concentrations of amylin (Fig. 2a). By contrast, cell proliferation that had been decreased by high physiological/pharmacological concentrations of amylin was attenuated by
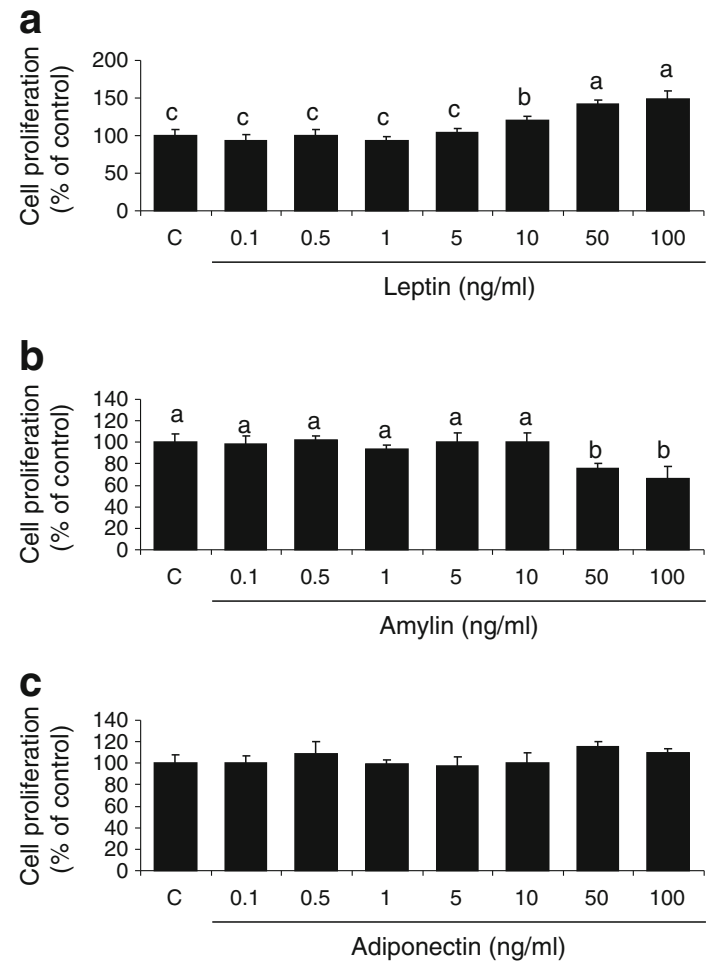

Fig. 1 Regulation of cell proliferation by leptin, amylin and adiponectin alone in mouse H19-7 HN cell lines. The cells were cultured as described in detail in the Methods. The cells were treated with leptin (a), amylin (b) or adiponectin (c) at indicated concentrations for $24 \mathrm{~h}$ and cell viability was then measured by the MTT assay as described in the Methods. All data were analysed using one-way ANOVA followed by the post-hoc test for multiple comparisons. Values are means \pm SD $(n=3)$. Means with different letters (above the bars) are significantly different $(p<0.05)$, whereas means with the same letters are not different from each other. $\mathrm{C}$, non-treated control

leptin administration (Fig. 2a). Also, we observed that leptin-increased cell proliferation was not altered by coadministration of adiponectin (Fig. 2b). Finally, we observed that amylin-decreased cell proliferation was not regulated by co-administration of adiponectin (Fig. 2c).

Activation of signal transducer and activator of transcription 3 signalling by leptin and amylin alone or in combination in mouse H19-7 HN cell lines Since adiponectin has no effect on leptin- or amylin-regulated cell proliferation (Figs 1,2), we decided to focus on leptin and amylin signalling in mouse H19-7 HN cell lines. We observed that amylin decreased activation of signal transducer and activator of transcription 3 (STAT3) in mouse H19-7 HN cell lines in a dosedependent manner (Fig. 3a). By contrast, STAT3 signalling was increased by leptin administration (Fig. 3a). Also, we observed that amylin-decreased STAT3 activation was attenuated by co-administration of leptin in mouse H19-7 HN cell lines (Fig. 3a). Based on this result, we chose a representative concentration of leptin $(50 \mathrm{ng} / \mathrm{ml})$ and amylin 

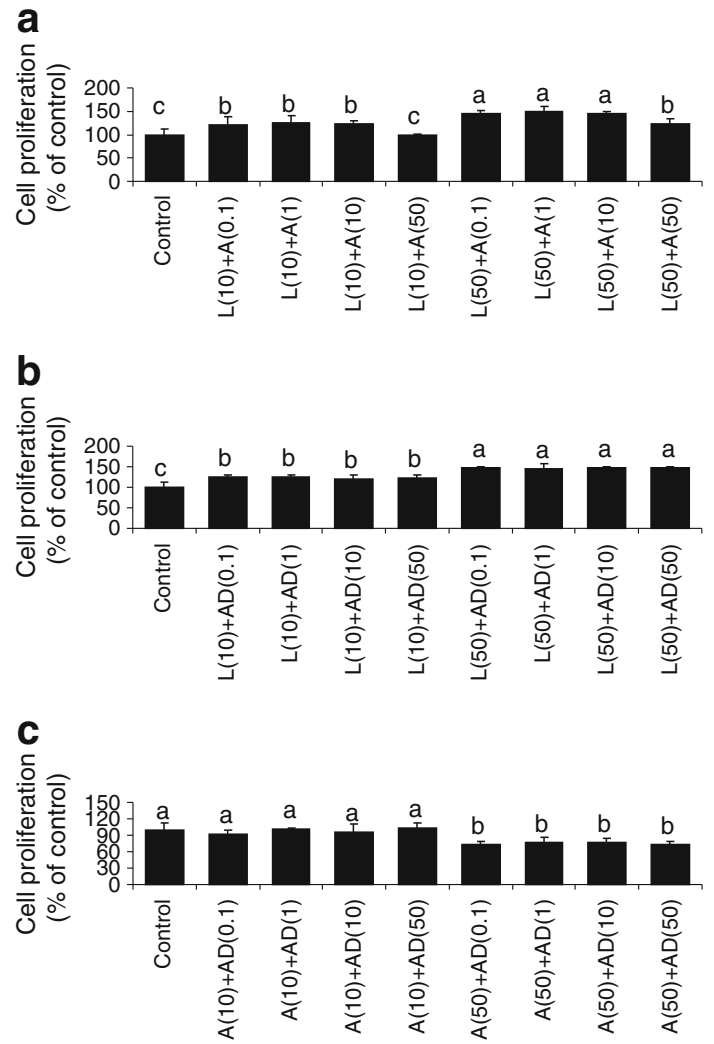

Fig. 2 Regulation of cell proliferation by leptin, amylin and adiponectin in combination in mouse H19-7 HN cell lines. The cells were cultured as described in detail in the Methods. The cells were treated with leptin+amylin (a), leptin+adiponectin (b) or amylin+adiponectin (c) at the indicated concentrations $(\mathrm{ng} / \mathrm{ml})$ for $24 \mathrm{~h}$ and cell viability was then measured by the MTT assay as described in detail in the Methods section. All data were analysed using one-way ANOVA followed by the post-hoc test for multiple comparisons. Values are means $\pm \operatorname{SD}(n=3)$. Means with different letters are significantly different $(p<0.05)$, whereas means with the same letters are not different from each other. A, amylin; $\mathrm{AD}$, adiponectin; L, leptin

$(50 \mathrm{ng} / \mathrm{ml})$ to determine whether a protective effect of leptin on amylin-decreased STAT3 activation is specific in mouse H19-7 HN cell lines. We observed that pre-treating the cells with specific STAT3 inhibitor, AG490, blocked leptin+ amylin-regulated STAT3 activation (Fig. 3b). Also, we confirmed that leptin-, amylin- and leptin+amylin-activated STAT3 signalling was blocked by administration of STAT3 siRNA (Fig. 3c). Similar to the results shown in Fig. 1, we observed that leptin, but not amylin, increased cell proliferation in mouse H19-7 HN cell lines (Fig. 3d). By contrast, leptin- and/or amylin-regulated cell proliferation is altered by pre-treatment with AG490 (Fig. 3d). Similarly, leptin-, amylin- and/or leptin + amylin-regulated cell proliferation is also diminished by AG490 administration (Fig. 3d). To confirm these results, we administered STAT3 siRNA and checked whether leptin-, amylin- or leptin+amylin-regulated cell proliferation was mediated by STAT3 signalling in mouse H19-7 HN cell lines (Fig. 3e). As expected, leptin-, amylin- and leptin + amylin-regulated cell proliferation was blocked by STAT3 siRNA administration. Moreover, these effects were specific since leptin+amylin-regulated cell proliferation was not changed by ssiRNA administration when compared with control (Fig. 3e), suggesting that leptin- and amylin-regulated cell proliferation is mediated by the STAT3 signalling pathway in mouse H19-7 HN cell lines.

Activation of AMPK and ERK signalling by leptin and amylin alone or in combination in mouse H19-7 HN cell lines We observed that amylin decreased AMP-activated protein kinase (AMPK) (electronic supplementary material [ESM] Fig. 1) and extracellular signal-regulated kinase (ERK) (ESM Fig. 2) activation in mouse H19-7 HN cell lines in a dose-dependent manner. By contrast, AMPK and ERK signalling was increased by leptin administration (ESM Figs 1, 2). Also, we observed that amylin-decreased AMPK and ERK activation was attenuated by coadministration of leptin in mouse H19-7 HN cells (ESM Figs 1,2), suggesting that in this cell line leptin- and amylinregulated cell proliferation is mediated by the AMPK and ERK signalling pathway.

Regulation of neurite outgrowth and synaptogenesis by leptin and amylin alone or in combination in mouse H19-7 $H N$ cell lines To determine whether leptin and amylin have a direct role in differentiation, cultured mouse H19-7 HN cell lines were incubated with leptin and amylin alone or in combination. We then performed immunocytochemical and western blotting analysis, and measured microtubuleassociated protein 2 (MAP2), a specific neurite outgrowth marker, and synapsin, a specific synaptogenesis marker. We observed that a considerable amount of MAP2 and synapsin in leptin-treated cells was detected when compared with control (Fig. 4 a, b). By contrast, amylin decreased the levels of MAP2 and synapsin (Fig. 4 a, b). Also, we observed that the amylin-decreased production of MAP2 and synapsin was attenuated by co-administration of leptin (Fig. 4 a, b). Next, we administered STAT3 siRNA and checked whether leptin- or amylin-regulated neurite outgrowth and synaptogenesis were mediated by STAT3 signalling in mouse H19-7 HN cell lines. We observed that leptin-, amylin- and leptin+amylin-regulated production of MAP2 and synapsin was blocked by STAT3 siRNA administration (Fig. 4a, b).

\section{Discussion}

The hippocampus has an important role in the brain function of humans and other vertebrates [9]. It belongs to the limbic system and plays an important part in the processing of information from short-term memory to long-term memory and spatial navigation [10-12]. In Alzheimer's disease, the 


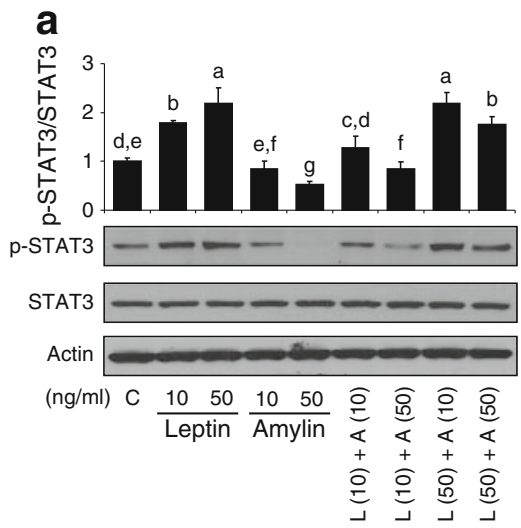

b

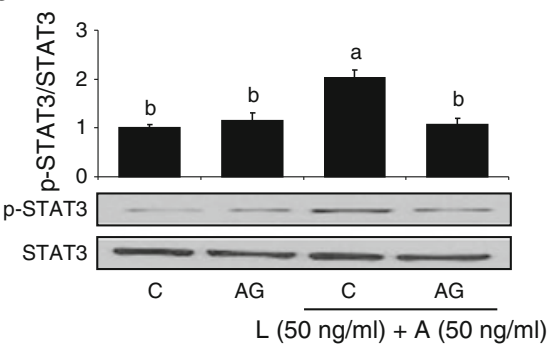

C



e

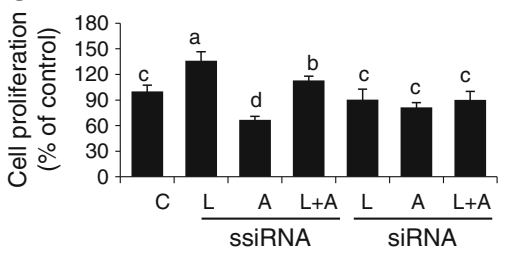

Fig. 3 Activation of STAT3 signalling by leptin and amylin alone or in combination in mouse H19-7 HN cell lines. (a-c) Western blots with densitometry shown above; (a) cells were treated with leptin and amylin alone or in combination at the indicated concentrations for $30 \mathrm{~min}$. Actin was used as a loading control. (b) The cells were pretreated with AG490 (AG, $1 \mu \mathrm{mol} / \mathrm{l}$ for $1 \mathrm{~h}$ ) and then treated with leptin+ amylin at the indicated concentrations for $30 \mathrm{~min}$. (c) The cells were transfected with ssiRNA or siRNA of STAT3 and then treated with leptin (50 ng/ml), amylin (50 ng/ml) or leptin+amylin for $30 \mathrm{~min}$. (d) The cells were pre-treated with AG490 (AG, $1 \mu \mathrm{mol} / 1$ for $1 \mathrm{~h}$ ) and then treated with leptin and amylin alone or in combination at the indicated concentrations hippocampus is one of the first regions of the brain to suffer damage; memory problems and disorientation appear among initial symptoms $[24,31]$. It has been shown that leptin facilitates spatial learning and memory [14-16] and that it produces antidepressant-like effects [17-22]. It has also been proposed that high levels of leptin are associated with lower rates of dementia and Alzheimer's disease [31]. Amylin acts at the level of the CNS to produce anorectic effects, alter physiological responses to feeding (and possibly thirst and drinking behaviour) [23] and drive the neurite for $24 \mathrm{~h}$. (e) The cells were transfected with ssiRNA or siRNA of STAT3 and then treated with leptin $(50 \mathrm{ng} / \mathrm{ml})$, amylin $(50 \mathrm{ng} / \mathrm{ml})$ or leptin+ amylin for $24 \mathrm{~h}$. The primary antibodies used were mouse monoclonal total STAT3, goat polyclonal phospho-STAT3 and mouse monoclonal $\beta$-actin. Secondary antibodies used were horseradish peroxidaseconjugated anti-mouse and anti-goat antibodies. All data were analysed using one-way ANOVA followed by the post-hoc test for multiple comparisons. Values are means \pm SD $(n=3)$. Means with different letters are significantly different $(p<0.05)$, whereas means with the same letters are not different from each other. A, amylin; C, non-treated control; L, leptin

degeneration in Alzheimer's disease [24]. Adiponectin has been proposed to exert multiple regulatory functions primarily through action on the CNS [26]. Adiponectin receptors are widely expressed in the brain, including the hippocampus, suggesting that adiponectin and/or other insulin-sensitising hormones may regulate brain function, particularly in processes related to memory and cognition [27]. It has also been shown that blood levels of adiponectin are reduced in individuals with primary cognitive disorders such as Alzheimer's disease and mild cognitive impairment. [32]. By contrast, the direct role of 
a
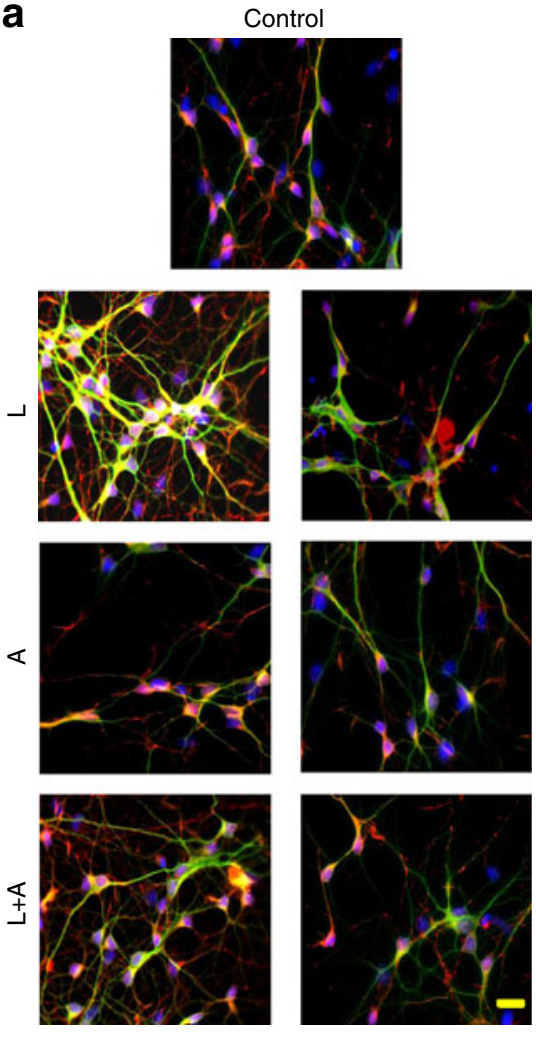

ssiRNA

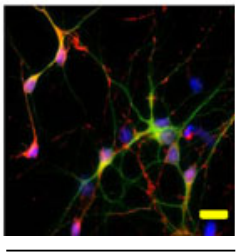

SiRNA

Fig. 4 Regulation of neurite outgrowth and synaptogenesis by leptin and amylin alone or in combination in mouse H19-7 HN cell lines. (a, b) The cells were transfected with ssiRNA or siRNA of STAT3 and then treated with leptin $(50 \mathrm{ng} / \mathrm{ml})$, amylin $(50 \mathrm{ng} / \mathrm{ml})$ or leptin + amylin for 5 days. Immunocytochemical analysis was carried out as described in the Methods. Green, MAP2; red, synapsin; blue, nucleus. All pictures were $\times 40$ magnification. (Scale bar $100 \mu \mathrm{m}$ ) Western blotting was performed as described in the Methods. The primary antibodies used

leptin, amylin and adiponectin in hippocampal neurogenesis has not yet been elucidated.

In this study, we observed that leptin has a protective effect on amylin-decreased neurite outgrowth and synaptogenesis in mouse H19-7 HN cell lines. We observed that leptin, but not amylin, stimulates hippocampal neurogenesis mainly through increased cell proliferation and differentiation in mouse H19-7 HN cell lines. Also, leptin and amylin signalling recruited STAT3/AMPK/ERK pathways, and inhibition of these signal transduction pathways led to the attenuation of the actions of leptin and amylin on proliferation and differentiation of mouse H19-7 HN cell lines, suggesting that a mechanism dependent on STAT3/AMPK/ERK activation mediates the actions of leptin and amylin on mouse hippocampal neurogenesis. We have also demonstrated that treatment of mouse H19-7 HN cells with adiponectin in physiological and pharmacological concentrations did not regulate cell proliferation.

Leptin has been implicated in several physiological processes involving the CNS in general and more specifically the

b
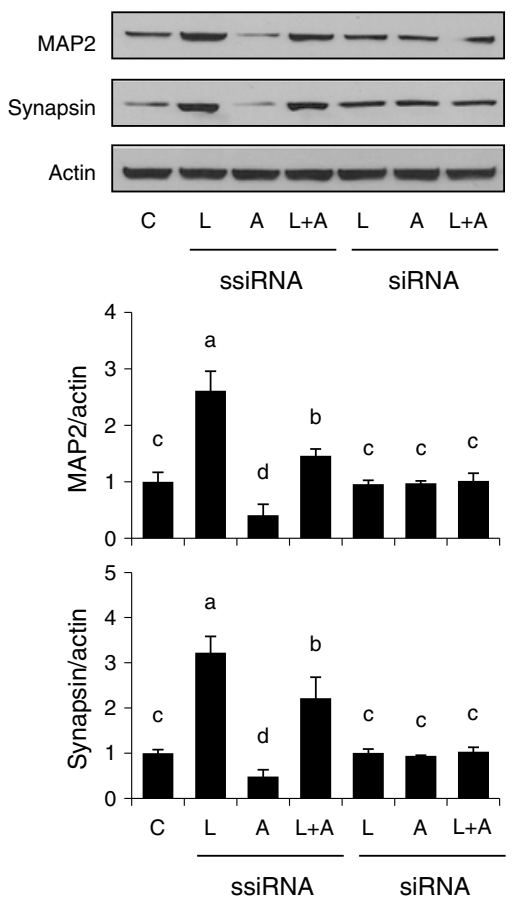

were mouse monoclonal MAP2, goat polyclonal synapsin and mouse monoclonal $\beta$-actin. Secondary antibodies used were horseradish peroxidase-conjugated anti-mouse and anti-goat antibodies. All data were analysed using one-way ANOVA followed by the post-hoc test for multiple comparisons. Values are means $\pm \operatorname{SD}(n=3)$. Means with different letters are significantly different $(p<0.05)$, whereas means with the same letters are not different from each other. A, amylin; C, non-treated control; L, leptin

hippocampus [33]. Also, it has been proposed that leptin increases adult hippocampal neurogenesis in vitro mainly by increasing cell proliferation [33, 34]. In agreement with these earlier observations, we observed herein that leptin increases cell proliferation in a dose-dependent manner. We have previously reported that treatment with leptin increases cell proliferation in mouse GT1-7 hypothalamic cell lines and that this effect is further increased by co-administration of amylin [35]. Hence, we speculated that amylin may have an additive or synergistic effect on leptin-increased cell proliferation in mouse H19-7 HN cell lines. However, we found that treatment with amylin decreases cell proliferation, indicating that pharmacological concentrations of amylin may have a neurotoxic effect in mouse H19-7 HN cell lines. By contrast, we observed that amylin-decreased cell proliferation is attenuated by coadministration of leptin, suggesting that leptin may have a protective effect on amylin-induced downregulation of hippocampal neurogenesis in mouse H19-7 HN cell lines. 
It has been proposed that co-administration of leptin and amylin in mice in vivo results in a multiplicative effect on STAT3 phosphorylation in the hypothalamus as compared with treatment with either of the hormones separately [36]. Also, we have demonstrated for the first time that leptin and amylin increase STAT3/AMPK/ERK signalling and that the effects of these two hormones are similar in magnitude, peaking at about the same time in mouse GT1-7 hypothalamic and $\mathrm{C}_{2} \mathrm{C}_{12}$ muscle cell lines in vitro [35] and in human adipose tissues and peripheral blood mononuclear cells ex vivo [30]. Moreover, it has been proposed that STAT3/AMPK/ERK signalling is important for the maintenance of neural development [37-40]. Based on these results, we checked whether leptin may interact with amylin and whether administration of amylin and leptin in combination could further increase leptinstimulated STAT3/AMPK/ERK signalling in mouse HT19-7 HN cells. Consistent with our previous human and mouse studies demonstrating that leptin-treated cells tend to have a greater number of cells positive for phosphorylated STAT3/ AMPK/ERK than controls [30,35], we observed herein that leptin increases STAT3/AMPK/ERK signalling in mouse HT19-7 HN cells. Unlike our previous mouse in vitro [35] and human ex vivo and in vitro studies [30], we found that amylin decreases STAT3/AMPK/ERK activation in mouse HT19-7 HN cells. By contrast, these effects were attenuated by co-administration of leptin, suggesting that leptin may have a protective effect by attenuating amylin-induced downregulation of STAT3/AMPK/ERK activation in mouse HT19-7 HN cells. Since STAT3 is a prototype signalling molecule downstream of the leptin receptor, which regulates food intake and body weight primarily in the hypothalamus [41-43], we next assessed whether leptin- and amylin-regulated cell proliferation is mediated by STAT3 signalling. We observed that depletion of STAT3 activation by a STAT3 inhibitor or by STAT3 siRNA administration blocked the effect of leptin on amylin-induced downregulation of STAT3 activation. Also, leptin- and amylinregulated cell proliferation was abolished by both STAT3 inhibitor and STAT3 siRNA administration, suggesting that leptin- and amylin-regulated cell proliferation in HT19-7 HN cells is mediated by STAT3 signalling.

We assessed whether amylin could interact with leptin in mouse HN development such as cell differentiation. We observed that leptin increased levels of both MAP2, a specific neurite outgrowth marker, and synapsin, a specific synaptogenesis marker. By contrast, amylin decreased the levels of MAP2 and synapsin and these effects were attenuated by coadministration of leptin. Activation of STAT3 has been reported to be associated with stimulated hippocampal neurogenesis [37] and is required for the neurotrophic effects of ciliary neurotrophic factor and leukaemia inhibitory factor on developing sensory neurons [38]. Based on these reports, we next assessed whether the protective effect of leptin on amylin-decreased cell differentiation was mediated by STAT3 signalling. We observed that the alteration in levels of MAP2 and synapsin by leptin and amylin alone or in combination was blocked by administration of STAT3 siRNA, suggesting that the protective effect of leptin on amylin-decreased neurite outgrowth and synaptogenesis in mouse H19-7 HN cell lines is mediated by STAT3 activation.

Overall, we have demonstrated that treatment of H19-7 $\mathrm{HN}$ cells with adiponectin in physiological and pharmacological concentrations did not regulate cell proliferation. We have also demonstrated herein that leptin increases mouse H19-7 HN cell proliferation and differentiation. Also, we observed that amylin may have a neurotoxic effect in mouse H19-7 HN cell lines. This is consistent with an earlier paper suggesting that full-length human amylin resulted in prominent toxicity in rat primary $\mathrm{HN}$ cells [24]. Also, it has been shown that, in contrast to full-length amylin, which promotes self-assembly and aggregation, various amylin peptide fragments (including amino acid residues 20-29) were non-toxic at similar concentrations in rat primary hippocampal cultures, suggesting that secondary structure may play a predominant role in human amylin neurotoxicity [24]. Hence, further work needs to be done using various amylin peptide fragments not only in hippocampal cells but also in hypothalamic cells. Moreover, we demonstrated for the first time that leptin has a protective effect on amylin-induced downregulation of hippocampal neurogenesis via the STAT3/AMPK/ERK signalling pathway in mouse H19-7 HN cell lines. Since the actions of leptin and amylin in vitro may differ from their actions in vivo, future work is needed to determine whether similar signalling mechanisms operate in vivo and whether hippocampal neurogenesis mediates the actions of leptin and/or amylin on hippocampal-related processing such as learning, memory and emotional responses. Limitations of this study include the fact that, although we studied the signalling pathways that are considered to be the primary targets of leptin and amylin in hippocamapal cells, we did not look at all possible signalling pathways. Thus, further work needs to be done in the future. Despite these limitations, our initial mechanistic data suggest a novel role for leptin and amylin in the processes of mouse hippocampal neurogenesis, providing new insights into the mechanisms of neurogenic regulation.

Funding The Mantzoros Laboratory was supported by the National Institute of Diabetes and Digestive and Kidney Diseases grants 58785, 79929 and 81913, and by Award No. 1I01CX000422-01A1 from the Clinical Science Research and Development Service of the Veterans Affairs (VA) Office of Research and Development.

Duality of interest The authors declare that there is no duality of interest associated with this manuscript. 
Contribution statement HSM, FD and CSM designed the study and analysed and interpreted data. HSM, FD and CSM drafted and revised the article critically for important intellectual content. CSM conceived the study. All authors read and approved the final manuscript.

\section{References}

1. Badman MK, Flier JS (2005) The gut and energy balance: visceral allies in the obesity wars. Science 307:1909-1914

2. Matarese G, Moschos S, Mantzoros CS (2005) Leptin in immunology. J Immunol 174:3137-3142

3. Pelleymounter MA, Cullen MJ, Baker MB et al (1995) Effects of the obese gene product on body weight regulation in ob/ob mice. Science 269:540-543

4. Roth JD, Maier H, Chen S, Roland BL (2009) Implications of amylin receptor agonism: integrated neurohormonal mechanisms and therapeutic applications. Arch Neurol 66:306-310

5. Ravussin E, Smith SR, Mitchell JA et al (2009) Enhanced weight loss with pramlintide/metreleptin: an integrated neurohormonal approach to obesity pharmacotherapy. Obesity (Silver Spring) 17:1736-1743

6. Moon HS, Chamberland JP, Aronis K, Tseleni-Balafouta S, Mantzoros CS (2011) Direct role of adiponectin and adiponectin receptors in endometrial cancer: in vitro and ex vivo studies in humans. Mol Cancer Ther 10:2234-2243

7. Maeda N, Shimomura I, Kishida K et al (2002) Diet-induced insulin resistance in mice lacking adiponectin/ACRP30. Nat Med 8:731-737

8. Kubota N, Terauchi Y, Yamauchi T et al (2002) Disruption of adiponectin causes insulin resistance and neointimal formation. J Biol Chem 277:25863-25866

9. Duman RS, Malberg J, Nakagawa S (2001) Regulation of adult neurogenesis by psychotropic drugs and stress. J Pharmacol Exp Ther 299:401-407

10. Gould E, Tanapat P, McEwen BS, Flugge G, Fuchs E (1998) Proliferation of granule cell precursors in the dentate gyrus of adult monkeys is diminished by stress. Proc Natl Acad Sci USA 95:3168-3171

11. McEwen BS (1999) Stress and hippocampal plasticity. Annu Rev Neurosci 22:105-122

12. Duman RS, Nakagawa S, Malberg J (2001) Regulation of adult neurogenesis by antidepressant treatment. Neuropsychopharmacology $25: 836-844$

13. Jacobs BL (2002) Adult brain neurogenesis and depression. Brain Behav Immun 16:602-609

14. Aou XL, Oomura S, Hori Y, Fukunaga KN, Hori T (2002) Impairment of long-term potentiation and spatial memory in leptin receptordeficient rodents. Neuroscience 113:607-615

15. Oomura Y, Hori N, Shiraishi T et al (2006) Leptin facilitates learning and memory performance and enhances hippocampal CA1 long-term potentiation and CaMK II phosphorylation in rats. Peptides 27:2738-2749

16. Farr SA, Banks WA, Morley JE (2006) Effects of leptin on memory processing. Peptides 27:1420-1425

17. Lu XY, Kim CS, Frazer A, Zhang W (2006) Leptin: a potential novel antidepressant. Proc Natl Acad Sci U S A 103:1593-1598

18. Lu XY (2007) The leptin hypothesis of depression: a potential link between mood disorders and obesity? Curr Opin Pharmacol 7:648-652

19. Raber J, Rola R, LeFevour A et al (2004) Radiation-induced cognitive impairments are associated with changes in indicators of hippocampal neurogenesis. Radiat Res 162:39-47

20. Shors TJ, Townsend DA, Zhao M, Kozorovitskiy Y, Gould E (2002) Neurogenesis may relate to some but not all types of hippocampal-dependent learning. Hippocampus 12:578-584

21. Shors TJ, Miesegaes G, Beylin A, Zhao M, Rydel T, Gould E (2001) Neurogenesis in the adult is involved in the formation of trace memories. Nature 410:372-376
22. Santarelli L, Saxe M, Gross C et al (2003) Requirement of hippocampal neurogenesis for the behavioral effects of antidepressants. Science 30:805-809

23. Riediger T, Rauch M, Schmid H (1999) Actions of amylin on subfornical organ neurons and on drinking behaviour in rats. Am J Physiol 276:R514-R521

24. May PC, Boggs LN, Fuson KS (1993) Neurotoxicity of human amylin in rat primary hippocampal cultures: similarity to Alzheimer's disease amyloid-beta neurotoxicity. J Neurochem 61:2330-2333

25. Morley JE, Flood JF, Farr SA, Perry HJ, Kaiser FE, Morley PM (1995) Effects of amylin on appetite regulation and memory. Can J Physiol Pharmacol 73:1042-1046

26. Hoyda TD, Samson WK, Ferguson AV (2009) Adiponectin depolarizes parvocellular paraventricular nucleus neurons controlling neuroendocrine and autonomic function. Endocrinology 50:832-840

27. Guillod-Maximin E, Roy AF, Vacher CM et al (2009) Adiponectin receptors are expressed in hypothalamus and colocalized with proopiomelanocortin and neuropeptide $\mathrm{Y}$ in rodent arcuate neurons. J Endocrinol 200:93-105

28. Hempel R, Onopa R, Convit A (2012) Type 2 diabetes affects hippocampus volume differentially in men and women. Diabetes Metabol Res Rev 28:76-83

29. Masaki T, Anan F, Shimomura T, Fujiki M, Saikawa T, Yoshimatsu H (2012) Association between hippocampal volume and serum adiponectin in patients with type 2 diabetes mellitus. Metabolism 61:1197-1200

30. Moon HS, Chamberland JP, Diakopoulos KN et al (2011) Leptin and amylin act in an additive manner to activate overlapping signaling pathways in peripheral tissues: in vitro and ex vivo studies in humans. Diabetes Care 34:132-138

31. Lee EB (2011) Obesity, leptin, and Alzheimer's disease. Ann N Y Acad Sci 1243:15-29

32. Diniz BS, Teixeira AL, Campos AC et al (2012) Reduced serum levels of adiponectin in elderly patients with major depression. J Psychiatr Res 46:1081-1085

33. Pérez-González R, Antequera D, Vargas T, Spuch C, Bolós M, Carro E (2011) Leptin induces proliferation of neuronal progenitors and neuroprotection in a mouse model of Alzheimer's disease. J Alzheim Dis 24(Suppl 2):17-25

34. Garza JC, Guo M, Zhang W, Lu XY (2008) Leptin increases adult hippocampal neurogenesis in vivo and in vitro. $\mathrm{J}$ Biol Chem 283:18238-18247

35. Moon HS, Chamberland JP, Mantzoros CS (2012) Amylin and leptin activate overlapping signalling pathways in an additive manner in mouse GT1-7 hypothalamic, $\mathrm{C}_{2} \mathrm{C}_{12}$ muscle and AML12 liver cell lines. Diabetologia 55:215-225

36. Turek VF, Trevaskis JL, Levin BE et al (2010) Mechanisms of amylin/ leptin synergy in rodent models. Endocrinology 151:143-152

37. Jung KH, Chu K, Lee ST et al (2006) Granulocyte colonystimulating factor stimulates neurogenesis via vascular endothelial growth factor with STAT activation. Brain Res 1073-1074:190-201

38. Alonzi T, Middleton G, Wyatt S et al (2001) Role of STAT3 and PI 3-kinase/Akt in mediating the survival actions of cytokines on sensory neurons. Mol Cell Neurosci 18:270-282

39. Park HG, Yi H, Kim SH et al (2011) The effect of cyclosporine A on the phosphorylation of the AMPK pathway in the rat hippocampus. Progr Neuro Psychopharmacol Biol Psychiatr 35:1933-1937

40. Fishbein M, Gov S, Assaf F et al (2012) Long-term behavioral and biochemical effects of an ultra-low dose of $\Delta(9)$-tetrahydrocannabinol (THC): neuroprotection and ERK signaling. Exp Brain Res 221:437-448

41. Schwartz MW, Woods SC, Porte D, Seeley RJ, Baskin DG (2000) Central nervous system control of food intake. Nature 404:661-671

42. Ahima RS, Saper CB, Flier JS, Elmquist JK (2000) Leptin regulation of neuroendocrine systems. Front Neuroendocrinol 21:263-307

43. Bates SH, Myers MG (2003) The role of leptin receptor signalling in feeding and neuroendocrine function. Trends Endocrinol Metabol 14:447-452 